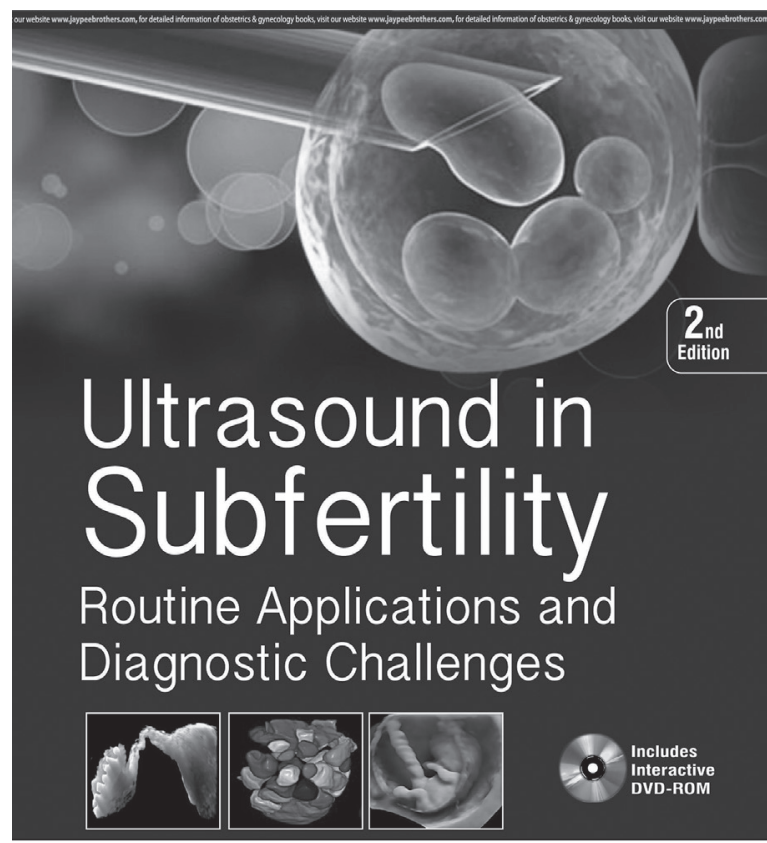

Edited by

K Jayaprakasan MBBS, MD, DNB, MRCOG, PhD Fertility Specialist (Fertility Unit Lead) Consultant Gynaecologist, Honorary Associate Professor Royal Derby Hospital and University of Nottingham, United Kingdom

Sonal Panchal MD (Radiology) Consultant Ultrasound Specialist Dr Nagori's Institute for Infertility and IVF, Ahmedabad, Gujarat, India

Professor Dubrovnik International University, Dubrovnik, Croatia Academic Director Ian Donald Inter-University School of Medical Ultrasound, India

\title{
Editors
}

K Jayaprakasan

Foreword Sonal Panchal Roy Homburg

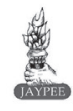

Publishers: Jaypee Brothers Medical Publishers (P) Ltd.

Also available online at www.jaypeebrothers.com

ISBN 978-93-5270-507-8

₹ 2798

\section{Ultrasound in Subfertility}

I must congratulate the authors to bring out the second edition of this book.The book starts with explanation of Ultrasound principles, examination techniques.The tips of using the best out of ultrasound machine have been described.Chapter on monitoring of IVF cycles and Ultrasound guided procedures are valuable for our knowledge. The latest three-dimensional ultrasound techniques have been described elegantly. It is a complete book for those practising infertility. Illustrations and color Doppler images are very complete and give complete understanding of the topic.

Keypoints help the readers get a summary of the subject.

Images enables readers to have a glimpse of subject in a short time. I recommend this manual in all libraries and for postgraduates and busy practitioners.

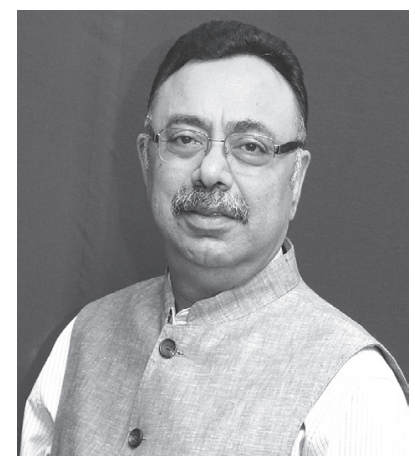

Narendra Malhotra

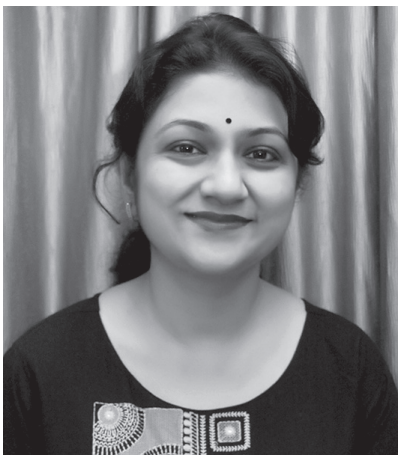

Ruchika Garg
Narendra Malhotra

Managing Director

Global Ranibow Healthcare Hospital

Agra, Uttar Pradesh, India

Ruchika Garg

Associate Professor

Department of Obstetrics \& Gynecology

SN Medical College

Agra, Uttar Pradesh, India 